\title{
GROWTH OF TERNARY AND QUATERNARY ZnSe COMPOUNDS WITH TRANSITION METALS BY CHEMICAL VAPOR TRANSPORT
}

E. JaniK, K. Grasza, A. Mycielski, J. BAzK-Misiuk, and J. KaChniarz

Institute of Physics, Polish Academy of Sciences

Al. Lotników 32/46, 02-668 Warszawa, Poland

Halogen transport method was applied to grow the crystals of solid solutions of $\mathrm{ZnSe}$ and transition metals at the temperature far below the melting point and phase transition temperature. The large crystals of $\mathrm{ZnMnSe}, \mathrm{ZnFeSe}, \mathrm{ZnNiSe}$ and $\mathrm{ZnFeSSe}$ were obtained. The technological parameters and shape of the quartz reactor were chosen for growth of a large crystal by self-nucleation; the transparent quartz furnace enabled the control of nucleation by visual observation. The parameters of crystal growth were determined. The crystal quality was estimated by X-ray diffraction method. The composition of crystals was determined by electron microprobe analysis and energy dispersive X-ray fluorescence analysis.

PACS numbers: $81.10 . \mathrm{Bk}, 78.55 . \mathrm{Et}$

The aim of our work was the application of chemical vapor transport (CVT) to growth of large single crystals of ZnSe ternary and quaternary solid solutions with some transition metals. The driving force of this work was the necessity to develop the studies on diluted magnetic semiconductors [1, 2].

For our experiments of growth of ZnSe ternary and quaternary compounds we chose the closed ampoule horizontal system with iodine as a transport agent and the transparent, quartz three-zone furnace. In this work we describe the technique that yielded large crystals of $\mathrm{ZnMnSe}, \mathrm{ZnFeSe}$, ZnNiSe, and $\mathrm{ZnFeSSe}$ solid solutions, and we present the results of characterization of these crystals.

The starting materials were synthesized in our laboratory and baked up to $830^{\circ} \mathrm{C}$ under the vacuum. The reaction quartz ampoule for crystal growth experiments was cleaned according to standard procedure [3-9]. $10 \mathrm{~g}$ of powder mixture of desired composition was loaded into the reactor ampoule with a known quantity of iodine (Merck $4 \mathrm{~N}$ ) using the procedure reported by Recker and Schoepe [10]. Inorder to create proper conditions for crystal nucleation we chose a cylindrical ampoule with a conical elongated tip. The crystals were grown in the transparent three-zone quartz furnace designedand fabricated in our laboratory. The furnace cross-section and the temperature profile is shown in Fig. 1. The temperature hump in the front of the growing crystal limits the risk of parasitic nucleations and ensures the growth with the stable solid/vapor interface [11].

The ampoule was first placed in a reversed temperature gradient in order to cause a reverse transport cleaning the walls of the nucleation region from condensation sits. After $20 \mathrm{~h}$ under this conditions, the tipped end of the ampoule 


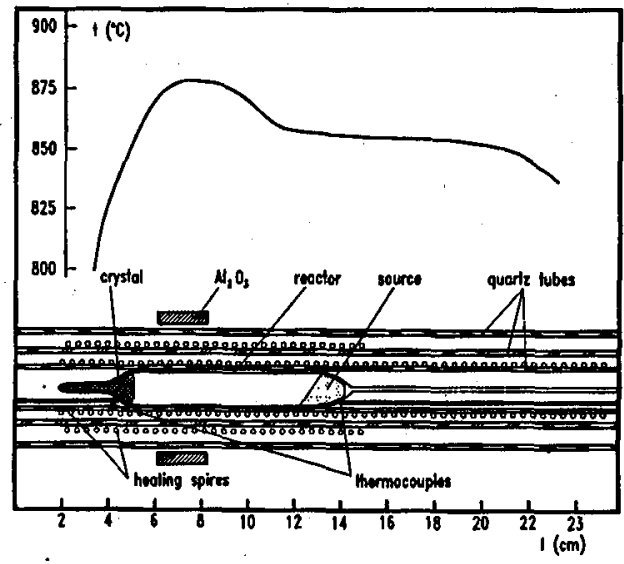

Fig. 1. Cross-section of the horizontal quartz furnace with a typical temperature profile.

was introduced in the desired temperature gradient; the source material was at the same moment situated in the constant temperature zone. The results of nucleation were visually observed and controlled up to the moment of apparition of nucleus. After the nucleus of 1-2 mm was formed, the crystal growth started. The ampoule was manually pulled from the furnace with the rate of about $1 \mathrm{~mm} /$ day. The optimal parameters of the system were as follows: $T_{\mathrm{s}}=850 \div 890^{\circ} \mathrm{C}, D_{\text {in }}=18.5 \mathrm{~mm}$, $L=100 \mathrm{~mm}, c_{\mathrm{t}}=5 \mathrm{mg} / \mathrm{ccm}$, where $T_{\mathrm{s}}$ is the mean source temperature, $D_{\text {in }}-$ diameter and $L$ - length of the ampoule, $c_{\mathrm{t}}$ - iodine concentration, respectively. The growth was stopped after about 20 days of process duration. The system was allowed to cool down from the growth temperature to the room temperature with the rate of $100^{\circ} \mathrm{C} / \mathrm{h}$.

The crystals from non-perturbed runs were about $30 \mathrm{~mm}$ long and of diameter up to $18 \mathrm{~mm}$. The parameters of our crystal growth runs are presented in Table. The mean transport rate was calculated dividing the weight of the crystal by the growth time. The composition of the crystals was determined by energy dispersive X-ray analysis. X-ray full width half maximum (FWHM) rocking curves using the double crystal diffractometer were measured on the natural faces of the crystals. All measured faces had (111) orientations and the value of the Bragg angle confirmed the pure cubic structure.

The electrical measurements show that crystals are of $p$-type and of high resistivity. The results of the transport phenomena measurements will be the subject of another presentation [12].

This work was supported in part by the Cornmitte for Scientific Research through grant No. 204759101 and Maria Skłodowska-Curie joint found II No. PAN/NSF-92-113. 


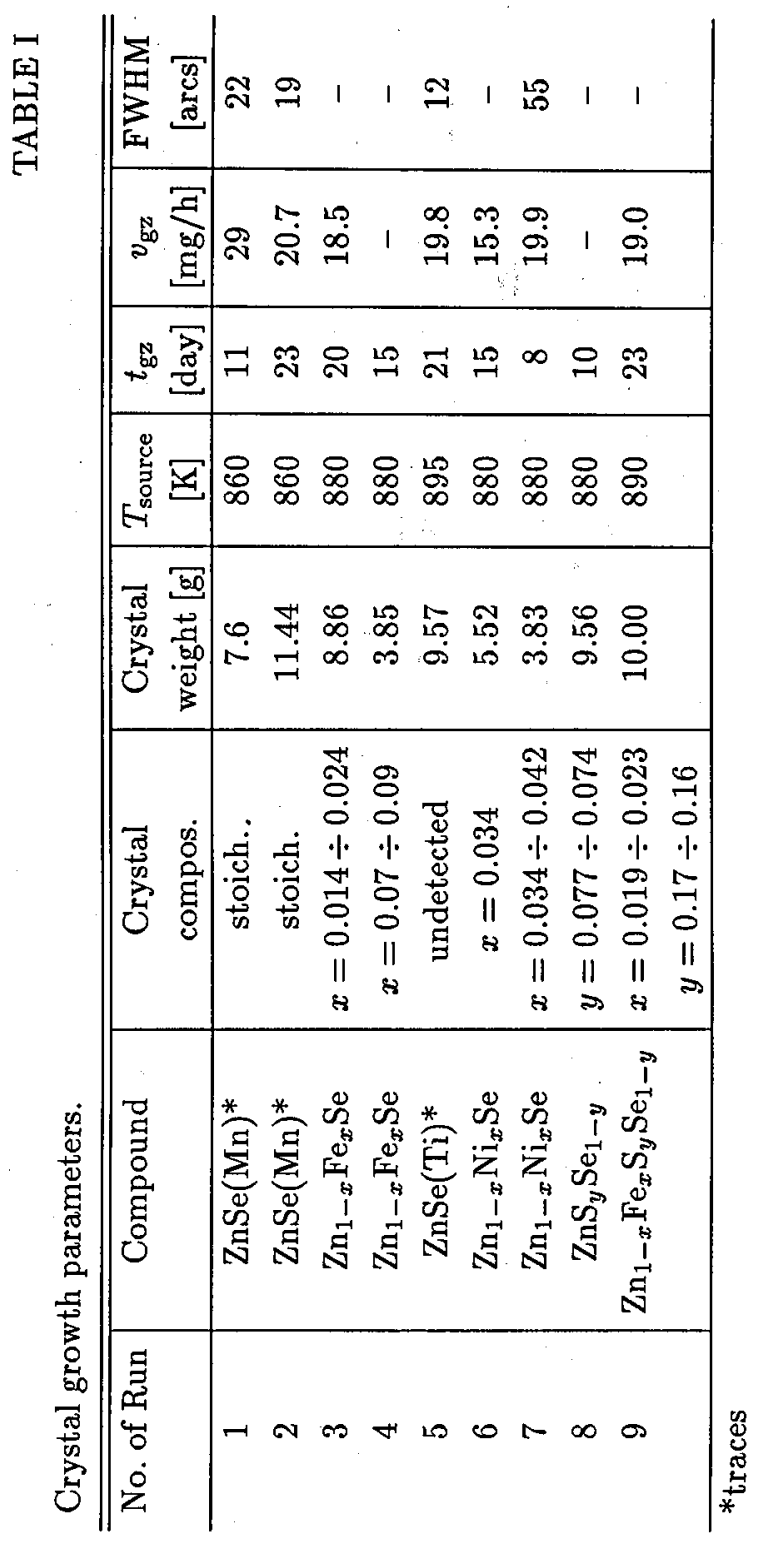




\section{References}

[1] A. Mycielski, W. Dobrowolski, A. Szadkowski, M. Borowiec, M. Arciszewska, C. Julien, C. Rigoux, M. Menant, in: Proc. 20th Int. Conf. on Physics of Semiconductors, Tessaloniki 1990, Eds. E.M. Anastassakis, J.D. Joannopulos, World Scientific Publ., Singapore 1990, p.702.

[2] A. Mycielski, M. Arciszewska, W. Dobrowolski, C. Rigoux, A. Mauger, C. Testelin, C. Julien, A. Lenard, M. Guillot, B. Witkowska, M. Menat, Phys. Scr. Vol. T 39, 119 (1991).

[3] H. Schafer, J. Cryst. Growth 9, 17 (1971).

[4] E. Kaldis, J. Phys. Chem. Solids 26, 1701 (1965).

[5] S.G. Parker, J. Cryst. Growth 9, 177 (1971).

[6] E. Kaldis, R. Widmer, J. Phys. Chem. Solids 26, 1697 (1965).

[7] S. Fujita, H. Mimoto, H. Takebe, T. Noguchi, J. Crystal Growth 47, 326 (1979).

[8] A. Catano, Z.K. Kun, J. Cryst. Growth 33, 324 (1976).

[9] H. Hartmann, J. Cryst. Growth 42, 144 (1977).

[10] K. Recker, R. Schoepe, J. Cryst. Growth 9, 189 (1971).

[11] K. Grasza, in: Elementary Crystal Growth, Ed. K. Sangwal, SAAN Publ., Lublin 1993, Chap. 2.

[12] A. Zaręba, E. Janik, A. Szadkowski, private communication. 